\title{
Identification of the Mouse T Cell ADP-Ribosylome Uncovers ARTC2.2 Mediated Regulation of CD73 by ADP-Ribosylation
}

\author{
Mario Leutert ${ }^{1,2 *}$, Yinghui Duan ${ }^{3}$, Riekje Winzer ${ }^{4}$, Stephan Menzel ${ }^{4,5}$, Eva Tolosa ${ }^{4}$, \\ Tim Magnus ${ }^{3}$, Michael O. Hottiger ${ }^{1}$, Friedrich Koch-Nolte ${ }^{4}$ and Björn Rissiek ${ }^{3 *}$ \\ ${ }^{1}$ Department of Molecular Mechanisms of Disease, University of Zurich, Zurich, Switzerland, ${ }^{2}$ Department of Genome Sciences, \\ University of Washington, Seattle, WA, United States, ${ }^{3}$ Department of Neurology, University Medical Centre Hamburg- \\ Eppendorf, Hamburg, Germany, ${ }^{4}$ Institute of Immunology, University Medical Centre Hamburg-Eppendorf, Hamburg, Germany, \\ ${ }^{5}$ Mildred Scheel Cancer Career Center HaTricS4, University Medical Center Hamburg-Eppendorf, Hamburg, Germany
}

\section{OPEN ACCESS}

Edited by: Jose Carlos Alves-Filho, University of São Paulo, Brazil

Reviewed by: Akio Ohta,

Foundation for Biomedical Research and Innovation, Japan Daniele Carvalho Nascimento, University of São Paulo, Brazil

*Correspondence: Björn Rissiek b.rissiek@uke.de Mario Leutert mleutert@uw.edu

Specialty section: This article was submitted to Cytokines and Soluble Mediators in Immunity, a section of the journal

Frontiers in Immunology

Received: 30 April 2021 Accepted: 02 August 2021 Published: 24 August 2021

Citation:

Leutert M, Duan Y, Winzer R, Menzel S, Tolosa E, Magnus T, Hottiger MO, Koch-Nolte F and Rissiek B (2021) Identification of the Mouse T Cell ADP-Ribosylome Uncovers ARTC2.2 Mediated Regulation of CD73 by ADP-Ribosylation.

Front. Immunol. 12:703719. doi: 10.3389/fimmu.2021.703719
Mouse T cells express the ecto-ADP-ribosyltransferase ARTC2.2, which can transfer the ADP-ribose group of extracellular nicotinamide adenine dinucleotide $\left(\mathrm{NAD}^{+}\right)$to arginine residues of various cell surface proteins thereby influencing their function. Several targets of ARTC2.2, such as P2X7, CD8a and CD25 have been identified, however a comprehensive mouse $\mathrm{T}$ cell surface ADP-ribosylome analysis is currently missing. Using the Af1521 macrodomain-based enrichment of ADP-ribosylated peptides and mass spectrometry, we identified 93 ADP-ribsoylated peptides corresponding to 67 distinct $T$ cell proteins, including known targets such as CD8a and CD25 but also previously unknown targets such as CD73. We evaluated the impact of ADPribosylation on the capability of $\mathrm{CD} 73$ to generate adenosine from adenosine monophosphate. Our results show that extracellular $\mathrm{NAD}^{+}$reduces the enzymatic activity of CD73 HEK cells co-transfected with CD73/ARTC2.2. Importantly, NAD ${ }^{+}$ significantly reduced CD73 activity on WT CD8 T cells compared to ARTC2ko CD8 T cells or WT CD8 T cells treated with an ARTC2.2-blocking nanobody. Our study provides a comprehensive list of $\mathrm{T}$ cell membrane proteins that serve as targets for ADPribosylation by ARTC2.2 and whose function may be therefore affected by ADP-ribosylation.

Keywords: NAD, CD73, ADP-ribosylation, T cells, ARTC2.2

\section{INTRODUCTION}

Ecto-ADP-ribosyltransferases (ARTCs) are cell surface enzymes that utilize extracellular nicotinamide adenine dinuleotide $\left(\mathrm{NAD}^{+}\right)$to covalently attach the $\mathrm{ADP}$-ribose group of $\mathrm{NAD}^{+}$ to arginine residues of various cell surface proteins under the release of nicotinamide $(1,2)$. The mouse ARTC family consist of six members: GPI-anchored ARTC1, ARTC2.1 and ARTC2.2, ARTC3, ARTC4 and the soluble ARTC5 (3). ARTC2.1 and ARTC2.2 are the ARTCs predominantly expressed by cells of the murine immune system (4). ARTC2.1 is highly expressed on the cell surface 
of innate immune cells such as macrophages and microglia (5) and to some extent on T cells (6). In contrast, ARTC2.2 is highly expressed on most $\mathrm{T}$ cell populations. Further, it is worth noting that the ARTC2.1 encoding gene, Art2a, is inactivated by a premature stop codon in the C57BL/6 (B6) mouse strain, whereas other strains such as Balb/c carry an intact Art2a gene (7). Therefore, in B6 mice, ecto-ARTC activity in the immune system is limited to the $\mathrm{T}$ cell compartment.

Results from ADP-ribosylation assays using ${ }^{32} \mathrm{P}_{-} \mathrm{NAD}^{+}$or etheno- $\mathrm{NAD}^{+}$as substrate, revealed that ARTC2.2 ADP-ribosylates a broad spectrum of membrane proteins (8-11). So far, a limited number of ARTC2.2 targets have been characterized. Among them are cell surface receptors such as the interleukin 2 (IL-2) receptor alpha subunit (CD25) (12) and the alpha chain of CD8 (CD8a) (13) molecule, both chains of the integrin LFA1 (11) and the ATP-gated ion channel P2X7 (14).

The functional impact of ADP-ribosylation on the target protein has been extensively studied in case of P2X7. ADPribosylation of $\mathrm{P} 2 \mathrm{X} 7$ mediates $\mathrm{NAD}^{+}$-induced cell death of $\mathrm{T}$ cells co-expressing ARTC2.2 and high levels of P2X7, such as regulatory T cells (Tregs), natural killer T cells, T follicular helper cells and tissue-resident memory T cells (14-19). Consistently, injection of $\mathrm{NAD}^{+}$induces temporary depletion of Tregs, thereby favoring anti-tumor responses (15). Cells expressing both ARTC2.2 and P2X7 are particularly affected by $\mathrm{NAD}^{+}$released during cell preparation procedures, i.e. isolation of $\mathrm{T}$ cells from spleen, resulting in extensive cell death in subsequent in vitro assays or upon adoptive cell transfer (20). Further, it has been shown that ADP-ribosylation of CD25 dampens IL-2 signalling by regulatory $\mathrm{T}$ cells, as the presence of $\mathrm{NAD}^{+}$reduced STAT1 phosphorylation in response to IL-2 stimulation (12). ADPribosylation of CD8a inhibits binding to MHCI and ADPribosylation of LFA-1 inhibits homotypic binding to LFA1 on other cells $(13,21)$

Apart from interference with target protein function, ADPribosylation can also affect the binding of monoclonal antibodies. For example, binding of clone 53-5.8 to CD8a is inhibited by ADP-ribosylation whereas clone $\mathrm{H} 35-17.2$ is unaffected (13). Similarly, ADP-ribosylation of P2X7 affects binding of clone Hano43, whereas clone Hano44 is unaffected (22).

The functional and technical consequences of ADP-ribosylation of cell surface proteins warrant proteomic investigation of the tissue- or cell-specific ADP-ribosylome. A comprehensive list of ADP-ribosylted target proteins opens the perspective to investigate the potential impact of this post-translational modification on the target protein function. For this, we recently developed a method combining Af1521 macrodomain-based enrichment of ADPribosylated peptides with mass spectrometry analyses to identify ADP-ribosylation sites across the proteome (23). Using this approach we previously generated ADP-ribosylomes of HeLa cells and mouse liver (23), mouse skeletal muscle and heart (24), mouse embryonic fibroblasts (25) and mouse microglia (26). The goal of this study was to subject mouse spleen $\mathrm{T}$ cells to a comprehensive ADP-ribsylome analyses in order to identify new targets of ARTC2.2-mediated cell surface protein ADPribosylation. From T cells incubated with $\mathrm{NAD}^{+}$, we identified 67
ADP-ribosylated target proteins, including 48 plasma membrane and $16 \mathrm{Golgi} / \mathrm{ER}$ proteins.

\section{MATERIAL AND METHODS}

\section{Mice}

C57BL/6 mice were used for all experiments. ARTC2ko mice (Art2b ${ }^{\text {tm1Fkn }}$, MGI\#2388827) (27) were backcrossed onto the C57BL/6J background for at least 12 generations. All mice were bred at the animal facility of the University Medical Center (UKE). All experiments involving tissue derived from animals were performed with approval of the responsible regulatory committee (Hamburger Behörde für Gesundheit und Verbraucherschutz, Veterinärwesen/Lebensmittelsicherheit, ORG722, N18/006). All methods were performed in accordance with the relevant guidelines and regulations.

\section{Preparation of Immune Cells}

Spleen and liver tissue were mashed through a cell strainer (50 $\mathrm{mL}$ falcon strainer, $70 \mu \mathrm{m}, \mathrm{GBO})$ using a syringe piston. Additionally, liver leukocytes were purified by running a percoll gradient. Cells were resuspended in $5 \mathrm{~mL} \mathrm{33 \%} \mathrm{percoll/}$ PBS in a $15 \mathrm{~mL}$ Falcon tube, and centrifuged at $1600 \mathrm{rpm}, 12^{\circ} \mathrm{C}$, for $20 \mathrm{~min}$. The pellet was washed once in PBS (ThermoFisher). Single cell suspensions were kept in FACS buffer containing $1 \mathrm{mM}$ EDTA (Sigma) and 0.1\% bovine serum albumin (Sigma). Erythrocytes were lyzed using an ACK lysis buffer $(155 \mathrm{mM}$ $\mathrm{NH}_{4} \mathrm{Cl}, 10 \mathrm{mM} \mathrm{KHCO} 3,0.1 \mathrm{mM}$ EDTA, pH 7.2). Peritoneal macrophages were harvested from the peritoneal cavity by lavage with $5 \mathrm{~mL}$ cold PBS $+1 \mathrm{mM}$ EDTA. In order to prevent $\mathrm{T}$ cell surface ADP-ribosylation during cell preparation, some mice were i.v. injected with $30 \mu \mathrm{g}$ of the ARTC2.2-blocking nanobody $\mathrm{s}+16 \mathrm{a}$ (28) $30 \mathrm{~min}$ prior to sacrificing.

\section{Antibodies and Flow Cytometry}

The following monoclonal antibodies were used for flow cytometric analyses: anti-CD3e-PE (clone 17A2, Biolegend), anti-ARTC2.2-AF647 [clone A109, Prof. Koch-Nolte (29)], anti-CD73-PE (clone TY/11.8, Biolegend), anti-CD8a-FITC (clone 53-6.7, Biolegend), anti-CD11b-FITC (clone M1/70, Biolegend). For protein harvesting, $\mathrm{CD}^{+} \mathrm{T}$ cells from spleen and liver were isolated by fluorescence activated cell sorting (FACS) on a BD FACS Aria III.

\section{T Cell Protein Harvesting}

FACS-sorted spleen T cells where subjected to ex vivo treatment with $50 \mu \mathrm{M} \mathrm{NAD}{ }^{+}$(Sigma) whereas a second preparation of spleen $\mathrm{T}$ cells and the liver $\mathrm{T}$ cells were left untreated in order to identify targets that were ADP-ribosylated during cell preparation (30). $\mathrm{NAD}^{+}$was washed away after $15 \mathrm{~min}$ of incubation at $4^{\circ} \mathrm{C}$ and cells were subsequently treated with ARTC2.2-blocking nanobody s+16a for 15 min to avoid ADPribosylation of cell surface proteins by intracellular ADPribosyltransferases during lysis with denaturing RIPA buffer (Sigma). 


\section{Proteomic Sample Preparation and ADP-Ribosylated Peptide Enrichment}

For buffer exchange, protein reduction, alkylation, poly to monoADP-ribose reduction by PARG (Poly(ADP-Ribose) Glycohydrolase) and tryptic digestion a modified FASP (filteraided sample preparation) protocol (31) was applied. For each sample 100-200 $\mu \mathrm{g}$ protein extracts were reduced in $1 \mathrm{mM}$ DTT for $30 \mathrm{~min}$ and subsequently transferred to a $0.5 \mathrm{~mL}$ molecular weight cut off centrifugal filter unit (Microcon-30kDa Milipore, Sigma) and centrifuged until all buffer was passed through the filter. Samples were alkylated for 15 min using urea buffer containing $20 \mathrm{mM}$ chloroacetamide and washed once with 100 $\mu \mathrm{L}$ urea buffer (8 M Urea, $0.1 \mathrm{M}$ Tris- $\mathrm{HCl} \mathrm{pH} \mathrm{8)} \mathrm{and} \mathrm{once} \mathrm{with}$ $100 \mu \mathrm{L}$ PARG buffer (50 mM Tris-HCL pH 8, $10 \mathrm{mM} \mathrm{MgCl}_{2}, 250$ $\mu \mathrm{M}$ DTT, $50 \mathrm{mM} \mathrm{NaCl}$ ). $0.5 \mu \mathrm{g}$ recombinant PARG enzyme (inhouse) in $100 \mu \mathrm{L}$ PARG buffer was added on to the filter and incubated for $1 \mathrm{~h}$. Filter was subsequently washed with $100 \mu \mathrm{L} 50$ $\mathrm{mM}$ ammonium bicarbonate buffer. On filter digestion was performed in $100 \mu \mathrm{L} 50 \mathrm{mM}$ ammonium bicarbonate using $5 \mu \mathrm{g}$ sequencing grade modified trypsin (Promega) at room temperature overnight.

ADP-ribosylated peptide enrichment was performed as previously described (23). The peptide mixture was diluted in PARG buffer (50 mM Tris-HCl, pH 8, $10 \mathrm{mM} \mathrm{MgCl}_{2}, 250 \mu \mathrm{M}$ DTT and $50 \mathrm{mM} \mathrm{NaCl}$ ) and binding was carried out for $2 \mathrm{~h}$ at $4^{\circ} \mathrm{C}$ using the Af1521 macrodomain GST-fusion protein coupled to glutathione-Sepharose beads. Beads were washed three times with PARG buffer and bound peptides were eluted three times with $0.15 \%$ TFA. The resulting mixture was desalted using stage tips packed with C18 filters.

\section{Mass Spectrometry Data Acquisition}

Samples were analyzed using an Orbitrap Q Exactive HF mass spectrometer (Thermo Fisher Scientific) coupled to a nano EasyLC 1000 (Thermo Fisher Scientific). Peptides were loaded onto a reverse-phase C18 (ReproSil-Pur $120 \mathrm{C} 18-\mathrm{AQ}, 1.9 \mu \mathrm{m}$, Dr. Maisch $\mathrm{GmbH})$ packed self-made column $(75 \mu \mathrm{m} \times 150$ $\mathrm{mm}$ ) that was connected to an empty Picotip emitter (New Objective, Woburn, MA). Solvent compositions in buffers A and $\mathrm{B}$ were $0.1 \%$ formic acid in $\mathrm{H} 2 \mathrm{O}$ and $0.1 \%$ formic acid in acetonitrile, respectively. Peptides were injected into the mass spectrometer at a flow rate of $300 \mathrm{~nL} / \mathrm{min}$ and were separated using a 90 min gradient of $2 \%$ to $25 \%$ buffer $\mathrm{B}$. The mass spectrometer was operated in data-dependent acquisition mode and was set to acquire full MS scans from $300-1700 \mathrm{~m} / \mathrm{z}$ at 60,000 resolution with an automated gain control (AGC) target value of $3 \times 10^{6}$ or a maximum injection time of $110 \mathrm{~ms}$. Charge state screening was enabled, and unassigned charge states and single charged precursors were excluded. The 12 most abundant ions on the full scan were selected for fragmentation using $2 \mathrm{~m} / \mathrm{z}$ precursor isolation window and beam-type collisional-activation dissociation (HCD) with $28 \%$ normalized collision energy. MS/ MS spectra were collected with AGC target value of $1 \times 10^{6}$ or a maximum injection time of $240 \mathrm{~ms}$. Fragmented precursors were dynamically excluded from selection for $20 \mathrm{~s}$.

\section{Mass Spectrometry Data Analysis}

MS and MS/MS spectra were converted to Mascot generic format (MGF) by use of Proteome Discoverer, v2.1 (Thermo Fisher Scientific). The MGFs were searched against the UniProtKB mouse database (taxonomy 10090, version 20160902), which included 24'905 Swiss-Prot, 34'616 TrEMBL entries, 59'783 reverse sequences, and 262 common contaminants. Mascot 2.5.1.3 (Matrix Science) was used for peptide sequence identification with previously described search settings (32). Enzyme specificity was set to trypsin, allowing up to four missed cleavages. The ADP-ribose variable modification was set to a mass shift of 541.0611, with scoring of the neutral losses equal to 347.0631 and 249.0862 . The marker ions at $\mathrm{m} / \mathrm{z}$ 428.0372, 348.0709, 250.0940, 136.0623 were ignored for scoring. $\mathrm{S}, \mathrm{R}, \mathrm{T}, \mathrm{K}, \mathrm{E}, \mathrm{D}$ and Y residues were set as variable ADP-ribose acceptor sites. Carbamidomethylation was set as a fixed modification on $\mathrm{C}$ and oxidation as a variable modification on M. Peptides are considered correctly identified when a mascot score $>20$ and an expectation value $<0.05$ are obtained. ADPribosylation sites were considered correctly localized with a localization probability of $>70 \%$.

\section{Bioinformatic Analyses}

For protein network visualization and GO enrichment analyses cytoscape (33), STRING database (v. 11) (34) and the cytoscape string app (35) were used. For the network visualization only highest confidence interactions are shown $(\geq 0.9)$ and proteins were clustered using the cytoscape string app.

\section{HEK Cell Transfection}

Human embryonic kidney (HEK) 293T cells were transfected with a pCMVSport6.1 plasmid encoding mouse Nt5e (CD73) using jetPEI transfection reagent (Polysciences Europe). Transfected cells were FACS-isolated every 3 - 4 days for high CD73 expression in order to generate stably transfected HEK cells. The stably transfected $\mathrm{CD}^{+} 3^{+}$HEK cells were then cotransfected with pME plasmid encoding for Art2b (ARTC2.2) in order to evaluate the impact of ADP-ribosylation on CD73 enzymatic activity.

\section{AMP Degradation Assay}

$1 \times 10^{4} \mathrm{HEK} 293 \mathrm{~T}$ cells were incubated with $50 \mu \mathrm{M} \mathrm{NAD}^{+}$on ice for $30 \mathrm{~min}$. Cells were washed with FACS buffer twice $(1410 \mathrm{rpm}$, $\left.5 \mathrm{~min}, 4^{\circ} \mathrm{C}\right)$. Cells were resuspended in $100 \mu \mathrm{L}$ FACS buffer, subsequently $100 \mu \mathrm{L}$ AMP were added to a final concentration of $10 \mu \mathrm{M}$ and incubated at room temperature for $40 \mathrm{~min}$. Cells were spin down (1410 rpm, $5 \mathrm{~min}, 4^{\circ} \mathrm{C}$ ) and $25 \mu \mathrm{L}$ supernatant was transferred to a solid white plate. $25 \mu \mathrm{L}$ AMP-Glo Reagent I were added per well, mixed and incubated at room temperature for 30 min. This was followed by addition of $50 \mu \mathrm{L}$ AMP-Glo Detection Solution per well and incubation for $60 \mathrm{~min}$ at room temperature. Plate was read with a plate-reading luminometer.

\section{HPLC CD73 Enzymatic Activity Assay}

To determine the AMPase activity by high performance liquid chromatography (HPLC), $0.2 \times 10^{6} \mathrm{CD}^{+} \mathrm{T}$ cells or peritoneal 
macrophages were incubated with $1 \mu \mathrm{M} 1, \mathrm{~N}^{6}$-etheno-AMP (eAMP, Biolog) for $30 \mathrm{~min}$ at $37^{\circ} \mathrm{C}$. After the incubation, cells were removed $\left(450 \times \mathrm{g}, 5 \mathrm{~min}, 4^{\circ} \mathrm{C}\right)$ and all samples were passed through $10 \mathrm{kDa}$ size exclusion filters $\left(10,000 \times \mathrm{g}, 10 \mathrm{~min}, 4^{\circ} \mathrm{C}\right.$, Pall Corporation) and stored at $-20^{\circ} \mathrm{C}$ until analyses. The analyses was performed on reversed-phase HPLC system (Agilent Technologies) with a $250 \mathrm{~mm} \times 4.6 \mathrm{~mm}$ C8 Luna column (5 $\mu \mathrm{m}$ particle size, Phenomenex) as stationary phase. The mobile phase consisted of different compositions of HPLC buffer $\mathrm{A}\left(20 \mathrm{mM} \mathrm{KH}_{2} \mathrm{PO}_{4}, \mathrm{pH} 6.0\right)$ and $\mathrm{B}$ (50\% buffer $\mathrm{A}, 50 \%$ methanol), and elution of the nucleotides from the column resulted from an increasing methanol content in the mobile phase $[0.0 \mathrm{~min}(0.0 \%$ buffer B), $5.0 \mathrm{~min}$ ( $0.0 \%$ buffer B), $27.5 \mathrm{~min}$ (100.0\% buffer B), 30.0 min (100.0\% buffer B), 32.0 min $(0.0 \%$ buffer B), 43.0 min ( $0.0 \%$ buffer B)]. The signals in both systems were detected by fluorescence detection (230 nm excitation wavelength, $410 \mathrm{~nm}$ emission wavelength). Different amounts of etheno-nucleotides (Biolog) were measured to quantify eAMP and the degradation product etheno-adenosine (eADO).

\section{Statistics and Software}

For statistical analyses, GraphPad Prism 8 was used. Two groups were compared using the student's t test. Multiple groups were compared using oneway ANOVA in combination with Dunnett's multiple comparison test. Analysis of flow cytometric data was performed using FlowJo (Treestar). The structure model of mouse CD73 (Q61503) was analyzed using Pymol software.

\section{RESULTS}

\section{Identification of Potential ARTC2.2 ADP-Ribosylation Targets on T Cells}

The aim of this study was to reveal potential ARTC2.2 ADPribosylation targets of mouse $\mathrm{T}$ cells. These proteins are most likely ADP-ribosylated on arginine residues facing the extracellular environment. Based on our previous studies $(24,26)$ we hypothesized that it is possible to detect ARTC2.2 mediated ADP-ribosylation by mass spectrometry even on proteins extracted from relatively small numbers of FACS-sorted $\mathrm{T}$ cells. We aimed to map ADP-ribosylated proteins of T cells isolated from mice under basal conditions [i.e. after encounter with endogenous extracellular $\mathrm{NAD}^{+}$in vivo or during cell preparation (30)] and after ex vivo treatment with exogenous $\mathrm{NAD}^{+}$. For this we applied our established mass spectrometry-based strategy with modifications to make it applicable to low sample input $(23,26)$.

$\mathrm{CD}^{+} \mathrm{T}$ cells were FACS sorted from seven spleens and livers of $\mathrm{C} 57 \mathrm{BL} / 6$ mice. Aliquots of cells were incubated for $15 \mathrm{~min}$ in the absence or presence of exogenous $\mathrm{NAD}^{+}$. To prevent ADPribosylation of intracellular proteins after cell lysis, cells were incubated with the ARTC2.2-blocking nanobody s+16a for 15 min before lysis with RIPA buffer. Proteins were subjected to filter-aided digestion and ADP-ribosylated peptides were enriched using the Af5121 macrodomain (Figure 1A). Samples were subsequently analyzed by mass spectrometry to identify peptides and to localize ADP-ribosyl modification sites. Importantly, we used higher-energy collisional dissociation (HCD) for peptide fragmentation, since this allows efficient identification of arginine ADP-ribosylated peptides due to the stability of ADP-ribosyl-arginine but is less effective in localizing serine and other O-linked ADP-ribosylations due to the lability of this modification type in $\operatorname{HCD}(24,32,36)$.

We identified 93 unique ADP-ribosylated peptides corresponding to 67 proteins (Supplementary Table 1). 49 ADP-ribosylated proteins were exclusively identified in $\mathrm{T}$ cells treated with $\mathrm{NAD}^{+}$(Figures 1B, C), 12 ADP-ribosylated proteins were found in both untreated and $\mathrm{NAD}^{+}$treated cells, $6 \mathrm{ADP}$-ribosylated proteins were only identified in the untreated conditions. We obtained confident ADP-ribose site localizations (localization probability $>70 \%$, considering R, S, T, Y, E, D, K as variable ADP-ribose amino acid acceptor sites) for 35 unique Rand $1 \mathrm{~S}$-ADP-ribosylation sites (Figure 1C).

Taken together, our approach allowed us to identify a considerable number of ADP-ribosylated proteins from a low number of $\mathrm{T}$ cells. We observed induction of R-ADP-

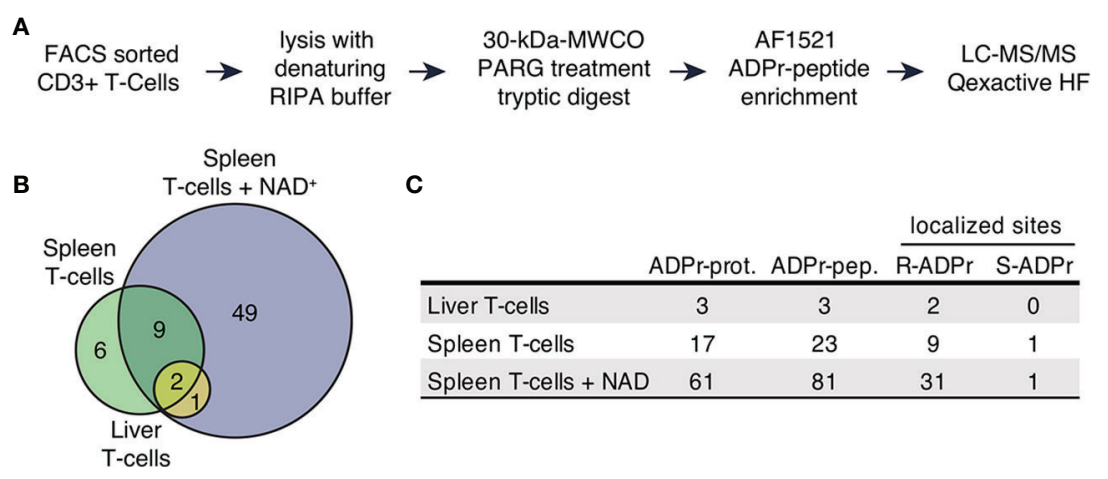

FIGURE 1 | The ADP-ribosylated proteome identified in T cells. (A) Schematic workflow of proteomic sample processing, digestion and ADPr-peptide enrichment tailored to the low input protein amount obtained from FACS sorted T cells. (B) ADP-ribosylated proteins identified in the three different sample types depicted in a Venn diagram. (C) Numbers of uniquely identified ADP-ribosylated proteins, unique ADP-ribosylated peptides and modified amino acids that were confidently localized (localization probability > 70\%). Modified arginine and serine sites were found. 
ribosylation upon treatment with exogenous $\mathrm{NAD}^{+}$indicating active ARTC2.2 on these cells.

\section{Exogenous NAD ${ }^{+}$Induces Extracellular ADP-Ribosylation of Proteins Relevant for the Immune Response}

To functionally cathegorize the identified ADP-ribosylation $\mathrm{T}$ cell target proteins, we performed gene-ontology (GO) term enrichment analysis, protein-protein interaction network visualization and literature comparisons. GO cellular component (GOCC) term enrichment analyses revealed strong enrichment for ADP-ribosylated proteins to be localized on the cell surface and plasma membrane (Figure 2A), providing further evidence that these proteins are most likely targets of ARTC2.2. Other significantly enriched cellular components were the endoplasmic reticulum and Golgi apparatus. GO biological processes (GOBP) were enriched in immune system processes, cell surface receptor signaling, cell adhesion and regulation of $\mathrm{T}$ cell activity (Figure 2A). Reactome pathway enrichment analysis provided additional separation of ADP-ribosylated proteins into more specific functional terms such as antigen presentation, signaling by interleukins, T cell receptor (TCR) signaling, and integrin cell surface interactions (Figure 2A).

Next, we performed protein level visualization of all identified ADP-ribosylated proteins by their association to Reactome pathway terms, relevant protein features, and protein-protein interactions. For this, we plotted the ADP-ribosylated proteins in form of a STRING network (Figure 2B) (34). ADP-ribosylated proteins with strong evidence for interactions among each other are connected with a grey line and proteins that had no interaction partners were preserved and shown as unconnected nodes. ADP-ribosylated proteins are color coded based on their affiliation to Reactome pathway terms identified in Figure 2A. ADP-ribosylated proteins are additionally marked if they are associated with the plasma membrane or cell surface (GOCC), are an ADP-ribosyltransferase or were already identified under basal conditions. The major hub of interacting proteins targeted by ADP-ribosylation was identified to have a role in TCR signaling, antigen presentation and cell surface integrin interactions. Connected to this cluster was Nt5e (5-primenucleotidase, CD73), a protein that hydrolyzes extracellular AMP to adenosine (37). An additional hub of interacting proteins consisted of the heteromeric IL-2 receptor complex, including IL2R $\alpha, \operatorname{IL} 2 \mathrm{R} \beta$ and IL2R $\gamma$ that were all found to be ADP-ribosylated after addition of $\mathrm{NAD}^{+}$. We have previously identified IL2R $\alpha$ as a target of ARTC2.2 and shown that its ADPribosylation functionally diminishes IL2 signaling (12). Most ADP-ribosylated proteins present at basal conditions were disconnected from these interaction hubs and less likely localized to the cell surface (Figure 2B). Two ADPribosyltransferases, ARTC2.2 (Art2b) and ARTD8/PARP14 (Parp14), were identified to be ADP-ribosylated, potentially by auto modification. Both were found to be ADP-ribosylated under basal and $\mathrm{NAD}^{+}$treated conditions. Proteomic identification of ADP-ribosylation sites on ARTCs have previously been observed in mouse liver on ARTC2.2 (23), in mouse microglia cells on
ARTC2.1 (26) and on ARTC1 in mouse heart and skeletal muscle tissues (24). ARTC (auto-)ADP-ribosylation can thus serve as a marker for ARTC activity. ADP-ribosylation by ARTD8/PARP14 has previously been associated with immune cell functions (38).

Next, we compared ADP-ribosylation levels of a few selected sites among the different conditions and with our previously published data on mouse liver (23) and microglia cells (26) (Figure 2C). ADP-ribosylation of CD73 at R149 was found exclusively on $\mathrm{T}$ cells treated with $\mathrm{NAD}^{+}$. Proteins that were identified in multiple different sample types showed modification on the same site (Pdia3, Slc44a2, Ptprc, Itgb2, Il2rg, H2-K1), or on additional sites (Ptprc, Itgb2, H2-K1) (Figure 2C). As exemplified by Pdia3 (a cytosolic protein exclusively modified on R62) and Slc44a2 (a multispan transmembrane protein exclusively modified on extracellular R130), R-ADPribosylation showed high site specificity on some proteins. In most of the analyzed cases, the R-ADP-ribosylation sites are located on the extracellular domain of the protein. An exception is the intracellular ARTD8/PARP14, which we found to be modified on S842 under basal and $\mathrm{NAD}^{+}$treated conditions, consistent with our recent observation that ARTD8/PARP14 is modified by O-linked ADP-ribosylation (24). In summary, we identified numerous $\mathrm{T}$ cell surface proteins with immune system relevant functions that are R-ADP-ribosylated, likely by ARTC2.2, in the presence of exogenous $\mathrm{NAD}^{+}$.

\section{ADP-Ribosylation of CD73 Reduces the Capability of CD8 T Cells to Generate Adenosine}

The majority of the identified T cell surface ADP-ribosylation targets are membrane proteins that act as receptors in cell signalling, antigen presentation or cell-cell adhesion. Apart from ARTC2.2 itself, CD73 was the only identified cell surface enzyme to be ADP-ribosylated. CD73 is expressed on several cell populations of the immune system, including regulatory $\mathrm{T}$ cells, $\mathrm{CD}^{+} \mathrm{T}$ cells and macrophages. It converts extracellular adenosine monophosphate (AMP) to adenosine (ADO) (Figure 3A), which acts as an immunosuppressant e.g. by inhibiting $\mathrm{T}$ cell proliferation (39). While ADP-ribosylation has been shown to impact the function of several cell surface receptors, little is known about the impact of ADP-ribosylation on the enzymatic activity of cell surface enzymes. Therefore, we investigated the impact of ADP-ribosylation on the catalytic activity of CD73. Analyses of the 3D structure model of mouse CD73 (Q61503) revealed that the identified ADP-ribosylation site R149 (red) is distant to the active site (yellow) of CD73 (Figure 3B).

We first tested the impact of CD73 ADP-ribosylation in HEK cells stably transfected with mouse CD73 upon transient cotransfection with an expression vector for ARTC2.2. We pretreated these cells with $\mathrm{NAD}^{+} 24 \mathrm{~h}$ after transfection, and FACS-sorted equal amounts of $\mathrm{CD}^{+} 3^{+} \mathrm{ARTC} 2.2^{-}$and $\mathrm{CD}^{+} 3^{+}$ARTC2.2 $2^{+}$HEK cells (Figure $3 \mathrm{C}$ ). The gates during cell collections were adjusted for equivalent cell surface levels of CD73 on ARTC2.2 $2^{-}$and ARTC2.2 ${ }^{+}$HEK cells. We then performed a comparative AMP degradation assay with the 

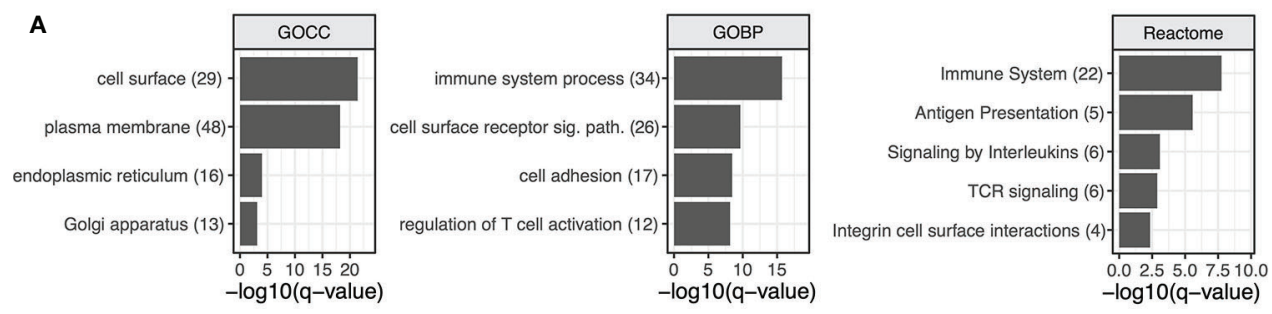

B

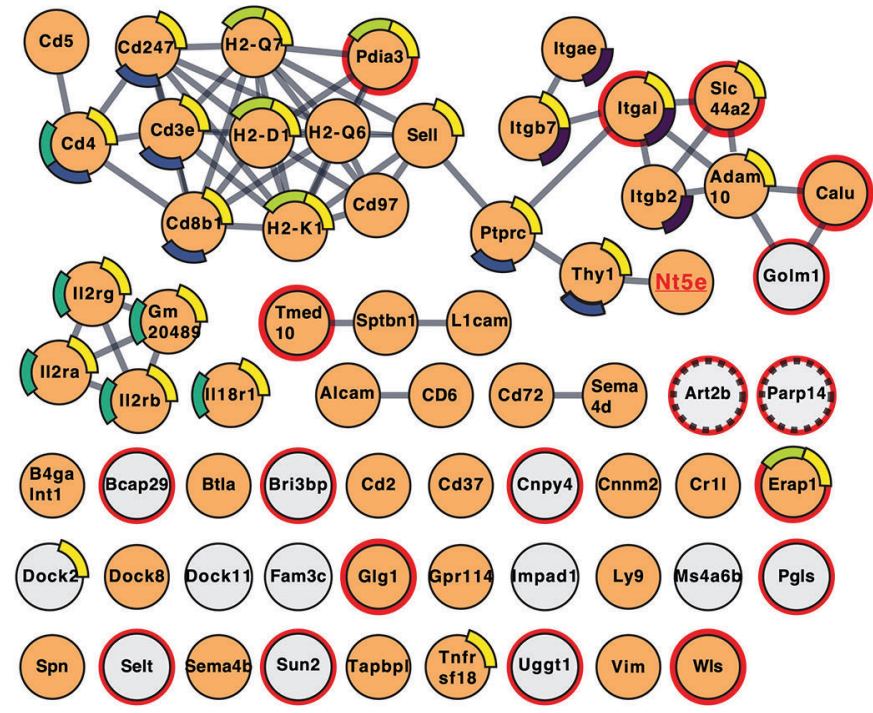

Reactome Pathway

Immune System

Antigen Presentation

Signaling by Interleukins

TCR signaling

Integrin interactions

Cell Surface \&

Plasma Membrane

*". ADP-ribosyl

transferases

present at

Nt5 $\underline{\underline{e}}$

Protein: 5'-nucleotidase

CD_antigen: CD73

C

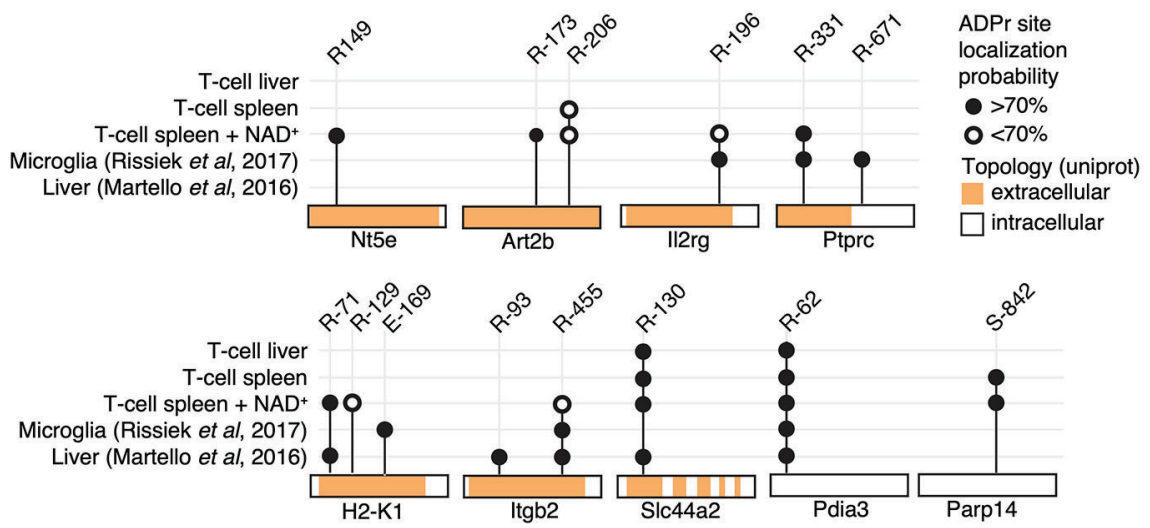

FIGURE 2 | Mouse T cell surface ADP-ribosylome analyses. (A) Gene ontology term enrichment was performed for ADP-ribosylated proteins identified in all conditions against the whole mouse genome. Gene ontology biological processes (GOBP), gene ontology cellular components (GOCC) and Reactome pathways were included. The q-values of selected and significantly enriched terms are plotted. Numbers of ADP-ribosylated proteins included in the specific terms are indicated in brackets. (B) STRING protein-protein interaction network of ADP-ribosylated proteins identified in all conditions. Gene names of ADP-ribosylated proteins are shown and high confidence protein-protein interactions (STRING interaction score $\geq 0.9$ ) are indicated with grey lines. Protein nodes are color coded by their affiliation to the Reactome pathways shown in (A) Proteins associated with the plasma membrane or cell surface are marked in orange. Proteins that were already identified under untreated conditions are marked with a red line and the two identified ADP-ribosyltransferases with a dashed line. CD73 that was chosen for follow up studies is highlighted. (C) ADP-ribosylation sites on selected proteins are plotted and compared to ADP-ribosylation sites identified in (23, 26).

collected CD73 ${ }^{+}$ARTC2 $22^{-}$and $\mathrm{CD}_{3}{ }^{+} \mathrm{ARTC} 2.2^{+}$HEK cells. We found that $\mathrm{NAD}^{+}$-treated $\mathrm{CD} 73^{+} \mathrm{ARTC} 2.2^{+}$cells were slightly but significantly less potent in degrading AMP than $\mathrm{NAD}^{+}$treated $\mathrm{CD} 73^{+} \mathrm{ARTC} 2.2^{-}$HEK cells (Figure 3C), consistent with an inhibitory effect of ADP-ribosylation on CD73 activity.
We next analyzed the impact of $\mathrm{NAD}^{+}$on the enzymatic activity of $\mathrm{CD} 73$ on primary $\mathrm{T}$ cells. For this we chose $\mathrm{CD} 8^{+} \mathrm{T}$ cells, which co-express ARTC2.2 and CD73, but are much less sensitive to $\mathrm{NAD}^{+}$-mediated cell death along the ARTC2.2/P2X7 axis when compared to Tregs (15). We isolated $\mathrm{CD}^{+} \mathrm{T}$ cells 
from untreated B6 WT mice, B6 WT mice treated with the ARTC2.2 blocking nanobody s+16a in order to block ARTC2.2 already in vivo, or from B6 ARTC2ko mice. Of note, cell surface levels of CD73 were comparable among WT and ARTC2.2ko $\mathrm{CD}^{+} \mathrm{T}$ cells (Figure 3D). Since $\mathrm{CD} 8^{+} \mathrm{T}$ cells express much lower cell surface levels of CD73 than CD73-transfected HEK cells, we used an HPLC-based assay measuring the CD73dependent generation of etheno-adenosine (eADO) from etheno-adenosine monophosphate (eAMP), as this was a more sensitive approach compared to the AMP degradation assay. We treated all three samples with $\mathrm{NAD}^{+}$and quantified the generation of eADO. Here, we observed that $\mathrm{NAD}^{+}$treated WT $\mathrm{CD}^{+} \mathrm{T}$ cells generated less eADO compared to $\mathrm{CD}^{+} \mathrm{T}$ cells from s+16a treated WT mice or from ARTC2.2ko mice (Figure 3D). Finally, we performed a similar assay with peritoneal macrophages that express high surface level of CD73 but lack ARTC2.2 expression. Here, $\mathrm{NAD}^{+}$-treated peritoneal macrophages of WT mice generate slightly but significantly more eADO compared to ARTC2ko macrophages, consistent with the fact that a larger fraction of WT peritoneal macrophages expressed high level of CD73 when compared to ARTC2ko peritoneal macrophages (Figure 3E). In summary, we could demonstrate that in an $\mathrm{NAD}^{+}$-rich environment, CD73 enzymatic activity is dampened on cells co-expressing ARTC2.2.

\section{DISCUSSION}

In this study we investigated the T cell ADP-ribosylome with a focus on ARTC2.2-mediated ADP-ribosylation of T cell surface proteins. We identified 67 ADP-ribosylated target proteins 48 of which are expressed at the cell surface and 16 of which in the ER or the Golgi apparatus. Of the identified ADP-ribosylation sites 35 were on arginine residues and 1 on a serine residue. Many of the identified target proteins are involved in immune system processes such as signalling, cell adhesion and regulation of $\mathrm{T}$ cell
A

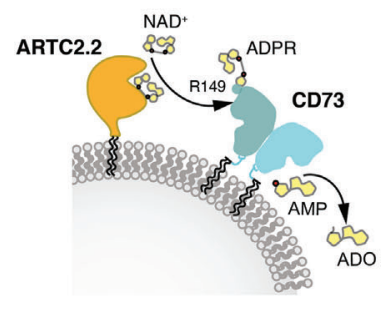

B

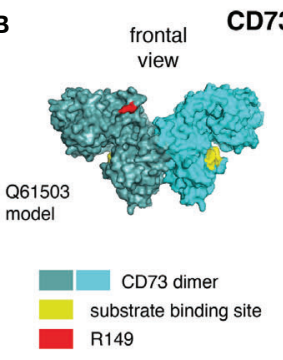

D

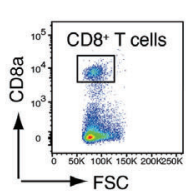

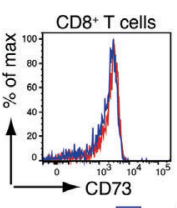

$\square$ WT $\square$ ARTC2ko

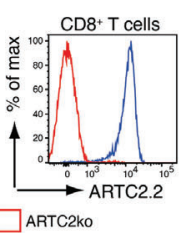

$\mathrm{CD}^{+} \mathrm{T}$ cells $+\mathrm{NAD}^{+}$
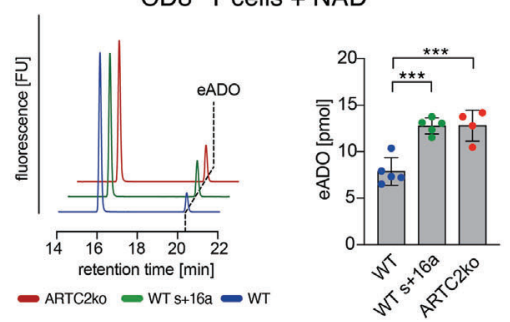

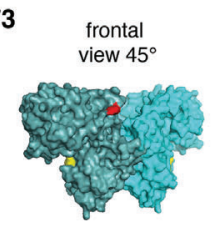

top view

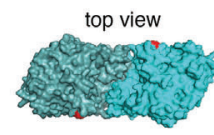

C NAD+treated
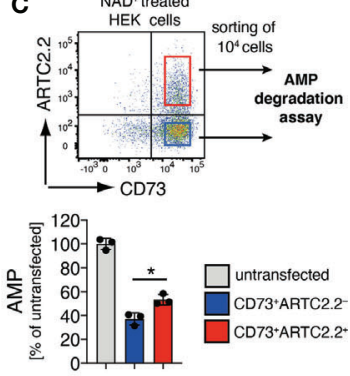

E

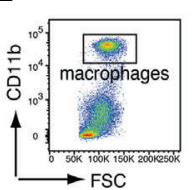

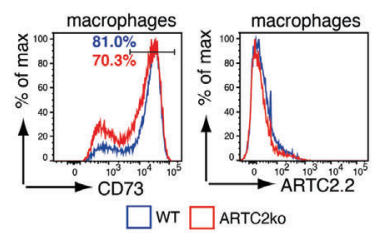

macrophages $+\mathrm{NAD}^{+}$

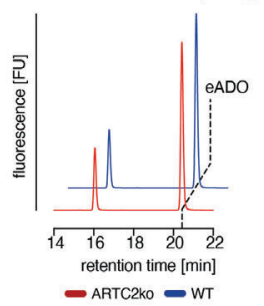

FIGURE 3 | ARTC2.2-dependent regulation of CD73 enzymatic activity. (A) CD73 can degrade adenosine monophosphate (AMP) to adenosine ADO. ARTC2.2 ADP-ribosylates CD73 at R149, potentially interfering with enzymatic activity. (B) The structure model Q61503 of a mouse CD73 dimer is shown in cyan. ADPribosylation site R149 (red) and substrate binding site (yellow) are indicated. (C) ARTC2.2 $2^{+} \mathrm{CD} 73^{+}$and ARTC2.2 $2^{-} \mathrm{CD} 73^{+} \mathrm{HEK}$ cells $(\mathrm{n}=3)$ were incubated with NAD ${ }^{+}$, FACS sorted and compared towards their capacity to degrade AMP in the AMPGlo assay. (D) Spleen CD8 ${ }^{+}$T cells from B6 WT, B6 WT treated with ARTC2.2blocking nanobody s+16a, and from ARTC2ko mice were analyzed towards CD73 and ARCT2.2 expression. After NAD treatment, FACS sorted cells $(n=4-5$ technical replicates) were further subjected to an HPLC-based assay to measure their capacity to generate etheno-ADO (eADO) from etheno-AMP (eAMP). (E) Peritoneal macrophages from B6 WT and ARTC2ko mice were analyzed towards CD73 and ARCT2.2 expression. After NAD treatment, FACS sorted cells ( $\mathrm{n}=$ 6 technical replicates) were analyzed for their capacity to generate eADO. Statistical comparison of the two groups was performed by using the Student's $t$ test, comparison of more than two groups was performed by using oneway ANOVA analyses with Dunnett's multiple comparisons $\left(p<0.05={ }^{*} / p<0.001={ }^{* \star \star}\right)$. Data represent results from two (C, E) or three (D) independent experiments. 
activity. It is conceivably that ADP-ribosylation modifies the function of many of these target proteins, thereby fine tuning immune reactions $(2,20)$. As an example, we analyzed the impact of ADP-ribosylation on the capacity of CD73 to hydrolyze AMP into adenosine. Our results indicate that ADPribosylation of $\mathrm{CD} 73$ leads to a reduced conversion of AMP to adenosine.

In our study we analyzed the ADP-ribosylome of $\mathrm{T}$ cells treated with or without exogenous $\mathrm{NAD}^{+}$. It is important to note that $\mathrm{NAD}^{+}$is also released during the preparation of murine $\mathrm{T}$ cells (30), which is sufficient to allow the ADP-ribosylation of T cell surface proteins. Therefore, we can not exclude that at least some of the observed ADP-ribosylated T cell surface proteins detected under basal conditions without addition of exogenous $\mathrm{NAD}^{+}$, such as Slc44a2 or Itgal, identified in untreated T cells from spleen or liver were modified during cell isolation. To further investigate whether the observed ADP-ribosylation of proteins occurred during the cell isolation or is catalyzed in vivo, systemic injection of the ARTC2.2 blocking nanobody s+16a prior to cell harvesting would prevent ADP-ribosylation during preparation $(17,28)$. However, this would also block ADPribosylation in vivo during the time between injection and the sacrifice of mice, but would not prevent de-ADP-ribosylation by enzymes. In order to identify further targets that are ADPribosylated in vivo it might thus be necessary to block deADP-ribosylation. Finally, it would also be interesting to compare the ADP-ribosylome of different $\mathrm{T}$ cell types such as $\mathrm{CD} 4^{+}$helper T cells, $\mathrm{CD} 4^{+}$regulatory T cells or cytotoxic $\mathrm{CD} 8^{+} \mathrm{T}$ cells as well as the ADP-ribosylome of the same $\mathrm{T}$ cell population from different organs, e.g. spleen and liver. However, this would probably need large amounts of cell material to start with.

Our analyses of proteins derived from $\mathrm{NAD}^{+}$treated $\mathrm{T}$ cells identified known and new targets of ARTC2.2-mediated ADPribosylation. We confirmed already known ARTC2.2 targets such as CD25 (Il2rg), CD8 $\beta$ (Cd8b) and CD45 (Ptprc). For CD25 we confirmed R196 (R178 in the mature protein) as ADP-ribosylation site, as reported in a previous study (12). Similarly, CD45 was found to be ADP-ribosylated on R331 of cells analyzed in the microglia study (26). Of note, the $\mathrm{T}$ cells used in this study were isolated from C57BL/6 (B6) mice, whereas the microglia study used cells from Balb/c mice. B6 mice carry a premature stop codon in the gene for the ARTC2.1 (40), and B6 T cells therefore exclusively express ARTC2.2 as cell surface ADP-ribosyltransferase (41). Balbc microglia express the thiol-activated ARTC2.1, but not ARTC2.2 and Balb/c T cells coexpress ARTC2.1 and ARTC2.2 $(5,6)$. The finding of the same ADP-ribosylated targets on microglia and $\mathrm{T}$ cells indicates that these two closely related ADP-ribosyltransferases may share common targets and modify common sites.

MHC class I (MHC-I) molecules are yet not well characterized regarding the potential impact of ADPribosylation. In this study we identified $\mathrm{H} 2-\mathrm{D}, \mathrm{H} 2-\mathrm{K}$ and the MHC-Ib molecule $\mathrm{H} 2-\mathrm{Q}$ to be ADP-ribosylated on $\mathrm{T}$ cells. MHC-I molecules present endogenous peptides to $\mathrm{CD}^{+} \mathrm{T}$ cells. Therefore, it would be interesting to test if MHC-I ADPribosylation affects its interaction with the $\mathrm{T}$ cell receptor (TCR) or loading of the peptide to form the MHC-I/peptide complex. Indeed, the identified R169 ADP-ribosylation site in H2-D1 is in close proximity to the TCR interaction surface (see PDB file $5 \mathrm{~m} 01)$. Further, a former study showed that ADP-ribosylation of the CD8 $\beta$ T cell coreceptor affects MHC-I/TCR interaction (13). It would thus be interesting to investigate, whether MHC-I ADPribosylation diminishes TCR binding in a similar fashion. Moreover, it is tempting to speculate that MHC-I ADPribosylation has an impact on TCR binding in an antigenspecific fashion: introduction of an ADP-ribose group at the MHC-I/TCR interaction site could lead to the activation of alternative $\mathrm{CD}^{+} \mathrm{T}$ cell clones that recognize this modified MHC-I/peptide complex. Future studies should address this hypothesis.

The list of ADP-ribosylation targets on T cells identified here is probably underestimated. The ATP gated P2X7 ion channel for example, a prominent and well characterized ARTC2.2 target on T cells (14), was not identified as target for ADP-ribosylation by our MS approach. P2X7 is expressed on regulatory T cells, NKT cells and CD4 effector/memory T cells $(15,17,42)-$ together these cells constitute only a minor fraction of the $\mathrm{T}$ cells analyzed here. Therefore, the amount of available P2X7 proteins might have been below the detectable threshold. Furthermore, it is possible that ADP-ribosylated peptides are lost during sample preparation or mass spectrometry analysis due to technical circumstances.

In this study, we focused on the functional impact of CD73 ADP-ribosylation. CD73 is a ecto- $5^{\prime}$-nucleotidase that generates immunosuppressive adenosine from AMP and thus plays a critical role in balancing the course of an inflammatory reaction (43). From a technical point of view, it is worth noting that adenosine is rapidly degraded to inosine by adenosine deaminase (ADA), both in vivo and in vitro. The etheno-adenosine (eADO) used in our HPLC-based assay to monitor and quantify CD73 enzymatic activity, however, is not a substrate for ADA (44) and therefore much more stable. Further, it has been recently shown that eADO is not taken up by cells via adenosine transporters (45). Therefore, differential degradation or uptake resulting in an experimental bias seems unlikely to explain the impact of $\mathrm{NAD}^{+}$on the $\mathrm{CD} 73$ enzymatic activity. The identified ADP-ribosylation site at R149 is distant from the active site of CD73 and is therefore likely to act allosterically. When comparing $\mathrm{CD}^{+} \mathrm{T}$ cells and macrophages, $\mathrm{NAD}^{+}$only had a dampening impact on the catalytic activity of CD73 on $\mathrm{CD}^{+} \mathrm{T}$ cells that co-express ARTC2.2 but not on macrophages that lack ARTC2.2. Therefore, CD73 ADP-ribosylation might be a T cellspecific mechanism that modulates CD73 activity in an $\mathrm{NAD}^{+}$ rich microenvironment, such as tumor tissue. Here, $\mathrm{NAD}^{+}$could be released along with ATP during tumor cell secondary necrosis. Indeed, prostate cancer cell lines have been reported to actively release intracellular $\mathrm{NAD}^{+}$into the culture medium (46). $\mathrm{CD}^{+} \mathrm{T}$ cells play a critical role in anti-tumor immune responses. CD73 on CD8 T cells seems to significantly contribute to the anti-tumor immunity response, since adoptively transferred CD73-deficient ovalbumin-specific OT-I T cells were more potent in killing OVA-expressing B16 melanoma tumors compared to 
WT OT-I T cells (47). This was accompanied by lower expression levels of the exhaustion markers programmed cell death protein 1 (PD-1) and CD39, strengthening the role of CD73 as an immune checkpoint and as a potential target in tumor therapy. Vice versa, it would be interesting to evaluate whether ARTC2-deficient OT-I $\mathrm{T}$ cells are less potent in killing OVA-expressing B16 melanoma, as CD73 activity would not be dampened by $\mathrm{NAD}^{+}$in the tumor environment.

Interestingly, both ARTC2.2 and CD73 can be shed from T cells $(48,49)$ and it has recently been shown that soluble ARTC2.2 can ADP-ribosylate various cytokines, including IFN $\gamma$ (50). Therefore, it would be interesting to elucidate whether soluble ARTC2.2 could also ADP-ribosylate the soluble form of CD73 and thereby control the cell-independent generation of adenosine.

\section{DATA AVAILABILITY STATEMENT}

The original contributions presented in the study are included in the article/Supplementary Material. Further inquiries can be directed to the corresponding authors.

\section{ETHICS STATEMENT}

The animal study was reviewed and approved by Hamburger Behörde für Gesundheit und Verbraucherschutz, Veterinärwesen/ Lebensmittelsicherheit.

\section{AUTHOR CONTRIBUTIONS}

BR and SM collected and prepared samples for mass spectrometry. ML performed mass spectrometry experiments, data collection and analyses. YD and RW performed CD73 functional assays. ET and TM assisted with CD73 functional assay data analyses and

\section{REFERENCES}

1. Bazan JF, Koch-Nolte F. Sequence and Structural Links Between Distant ADP-Ribosyltransferase Families. Adv Exp Med Biol (1997) 419:99-107. doi: 10.1007/978-1-4419-8632-0_12

2. Koch-Nolte F, Adriouch S, Bannas P, Krebs C, Scheuplein F, Seman M, et al. ADP-Ribosylation of Membrane Proteins: Unveiling the Secrets of a Crucial Regulatory Mechanism in Mammalian Cells. Ann Med (2006) 38:188-99. doi: 10.1080/07853890600655499

3. Glowacki G, Braren R, Firner K, Nissen M, Kühl M, Reche P, et al. The Family of Toxin-Related Ecto-ADP-Ribosyltransferases in Humans and the Mouse. Protein Sci (2002) 11:1657-70. doi: 10.1110/ps.0200602

4. Koch-Nolte F, Kernstock S, Mueller-Dieckmann C, Weiss MS, Haag F. Mammalian ADP-Ribosyltransferases and ADP-Ribosylhydrolases. Front Biosci (2008) 13:6716. doi: 10.2741/3184

5. Hong S, Braß A, Seman M, Haag F, Koch-Nolte F, Dubyak GR. Lipopolysaccharide, IFN-Gamma, and IFN-Beta Induce Expression of the Thiol-Sensitive ART2.1 Ecto-ADP-Ribosyltransferase in Murine Macrophages. J Immunol (2007) 179:6215-27. doi: 10.4049/jimmunol.179.9.6215

6. Hong S, Braß A, Seman M, Haag F, Koch-Nolte F, Dubyak GR. Basal and Inducible Expression of the Thiol-Sensitive ART2.1 Ecto-ADP- interpretation. FK-N and $\mathrm{MH}$ supervised the experiments and assisted with data interpretation and manuscript preparation. BR and ML assembled the figures and wrote the manuscript, which has been reviewed by all authors. All authors contributed to the article and approved the submitted version.

\section{FUNDING}

This work was funded by the Deutsche Forschungsgemeinschaft (DFG, German Research Foundation) - Project-ID: 335447717 SFB 1328 to FK-N (A10, Z2), TM (A13) and ET (A13/A14), a grant from "Hermann und Lilly Schilling-Stiftung für Medizinische Forschung" to TM, ADP-ribosylation research in the laboratory of $\mathrm{MH}$ is funded by the Kanton of Zurich and the Swiss National Science Foundation (grant 31003A_176177). ML is supported by a postdoctoral fellowship from the Swiss National Science Foundation (grant P400PB_194379). SM is supported by a grant of the Mildred Scheel Cancer Career Center HaTriCS4.

\section{ACKNOWLEDGMENTS}

The authors would like to thank Peter Gehrig, Paolo Nanni, Christian Panse, and Jonas Grossmann (Functional Genomics Center of the University of Zurich) for help with the mass spectrometry measurements and data analysis, the lab of Andreas Guse (UKE Hamburg, Germany) for assistance with the HPLC measurements, and the HEXT FACS Core Facility (UKE Hamburg, Germany) for cell sorting.

\section{SUPPLEMENTARY MATERIAL}

The Supplementary Material for this article can be found online at: https://www.frontiersin.org/articles/10.3389/fimmu.2021.703719/ full\#supplementary-material

Ribosyltransferase in Myeloid and Lymphoid Leukocytes. Purinergic Signal (2009) 5:369-83. doi: 10.1007/s11302-009-9162-2

7. Kanaitsuka T, Bortell R, Stevens LA, Moss J, Sardinha D, Rajan TV, et al. Expression in BALB/c and C57BL/6 Mice of Rt6-1 and Rt6-2 ADPRibosyltransferases That Differ in Enzymatic Activity: C57BL/6 Rt6-1 Is a Natural Transferase Knockout. J Immunol (1997) 159:2741-9.

8. Krebs C, Koestner W, Nissen M, Welge V, Parusel I, Malavasi F, et al. Flow Cytometric and Immunoblot Assays for Cell Surface ADP-Ribosylation Using a Monoclonal Antibody Specific for Ethenoadenosine. Anal Biochem (2003) 314:108-15. doi: 10.1016/S0003-2697(02)00640-1

9. Menzel S, Adriouch S, Bannas P, Haag F, Koch-Nolte F. Monitoring Expression and Enzyme Activity of Ecto-ARTCs. Methods Mol Biol (2018) 1813:167-86. doi: 10.1007/978-1-4939-8588-3_11

10. Koch-Nolte F, Petersen D, Balasubramanian S, Haag F, Kahlke D, Willer T, et al. Mouse T Cell Membrane Proteins Rt6-1 and Rt6-2 are Arginine/Protein Mono(ADPribosyl)transferases and Share Secondary Structure Motifs With ADP-Ribosylating Bacterial Toxins. J Biol Chem (1996) 271:7686-93. doi: 10.1074/jbc.271.13.7686

11. Okamoto S, Azhipa O, Yu Y, Russo E, Dennert G. Expression of ADPRibosyltransferase on Normal T Lymphocytes and Effects of Nicotinamide Adenine Dinucleotide on Their Function. J Immunol (1998) 160:4190-8. 
12. Teege S, Hann A, Miksiewicz M, MacMillan C, Rissiek B, Buck F, et al. Tuning IL-2 Signaling by ADP-Ribosylation of CD25. Sci Rep (2015) 5:8959. doi: 10.1038/srep08959

13. Lischke T, Schumacher V, Wesolowski J, Hurwitz R, Haag F, Koch-Nolte F, et al. CD8- $\beta$ ADP-Ribosylation Affects CD8(+) T-Cell Function. Eur J Immunol (2013) 43:1828-38. doi: 10.1002/eji.201243231

14. Seman M, Adriouch S, Scheuplein F, Krebs C, Freese D, Glowacki G, et al. NAD-Induced T Cell Death: ADP-Ribosylation of Cell Surface Proteins by ART2 Activates the Cytolytic P2X7 Purinoceptor. Immunity (2003) 19:57182. doi: $10.1016 / \mathrm{S} 1074-7613(03) 00266-8$

15. Hubert S, Rissiek B, Klages K, Huehn J, Sparwasser T, Haag F, et al. Extracellular NAD+ Shapes the Foxp3+ Regulatory T Cell Compartment Through the ART2P2X7 Pathway. J Exp Med (2010) 207:2561-8. doi: 10.1084/jem.20091154

16. Kawamura H, Aswad F, Minagawa M, Govindarajan S, Dennert G. P2X7 Receptors Regulate NKT Cells in Autoimmune Hepatitis. J Immunol (2006) 176:2152-60. doi: 10.4049/jimmunol.176.4.2152

17. Rissiek B, Danquah W, Haag F, Koch-Nolte F. Technical Advance: A New Cell Preparation Strategy That Greatly Improves the Yield of Vital and Functional Tregs and NKT Cells. J Leukoc Biol (2014) 95:543-9. doi: 10.1189/jlb.0713407

18. Georgiev H, Ravens I, Papadogianni G, Malissen B, Förster R, Bernhardt G. Blocking the ART2.2/P2X7-System Is Essential to Avoid a Detrimental Bias in Functional CD4 T Cell Studies. Eur J Immunol (2018) 48:1078-81. doi: $10.1002 /$ eji.201747420

19. Rissiek B, Lukowiak M, Raczkowski F, Magnus T, Mittrücker H-W, KochNolte F. In Vivo Blockade of Murine ARTC2.2 During Cell Preparation Preserves the Vitality and Function of Liver Tissue-Resident Memory T Cells. Front Immun (2018) 9:1580. doi: 10.3389/fimmu.2018.01580

20. Rissiek B, Haag F, Boyer O, Koch-Nolte F, Adriouch S. ADP-Ribosylation of P2X7: A Matter of Life and Death for Regulatory T Cells and Natural Killer T Cells. Curr Top Microbiol Immunol (2015) 384:107-26. doi: 10.1007/82_2014_420

21. Nemoto E, Yu Y, Dennert G. Cell Surface ADP-Ribosyltransferase Regulates Lymphocyte Function-Associated Molecule-1 (LFA-1) Function in T Cells. J Immunol (1996) 157:3341-9.

22. Rissiek B, Stabernack J, Cordes M, Duan Y, Behr S, Menzel S, et al. Astrocytes and Microglia Are Resistant to NAD+-Mediated Cell Death Along the ARTC2/P2X7 Axis. Front Mol Neurosci (2019) 12:330. doi: 10.3389/ fnmol.2019.00330

23. Martello R, Leutert M, Jungmichel S, Bilan V, Larsen SC, Young C, et al. Proteome-Wide Identification of the Endogenous ADP-Ribosylome of Mammalian Cells and Tissue. Nat Commun (2016) 7:12917. doi: 10.1038/ ncomms 12917

24. Leutert M, Menzel S, Braren R, Rissiek B, Hopp A-K, Nowak K, et al. Proteomic Characterization of the Heart and Skeletal Muscle Reveals Widespread Arginine ADP-Ribosylation by the ARTC1 Ectoenzyme. Cell Rep (2018) 24:1916-1929.e5. doi: 10.1016/j.celrep.2018.07.048

25. Abplanalp J, Leutert M, Frugier E, Nowak K, Feurer R, Kato J, et al. Proteomic Analyses Identify ARH3 as a Serine Mono-ADP-Ribosylhydrolase. Nat Commun (2017) 8:2055. doi: 10.1038/s41467-017-02253-1

26. Rissiek B, Menzel S, Leutert M, Cordes M, Behr S, Jank L, et al. Ecto-ADPRibosyltransferase ARTC2.1 Functionally Modulates Fc $\gamma r 1$ and Fc $\gamma r 2 b$ on Murine Microglia. Sci Rep (2017) 7:16477. doi: 10.1038/s41598-017-16613-w

27. Ohlrogge W, Haag F, Löhler J, Seman M, Littman DR, Killeen N, et al. Generation and Characterization of Ecto-ADP-Ribosyltransferase ART2.1/ ART2.2-Deficient Mice. Mol Cell Biol (2002) 22:7535-42. doi: 10.1128/ MCB.22.21.7535-7542.2002

28. Koch-Nolte F, Reyelt J, Schössow B, Schwarz N, Scheuplein F, Rothenburg S, et al. Single Domain Antibodies From Llama Effectively and Specifically Block T Cell Ecto-ADP-Ribosyltransferase ART2.2 In Vivo. FASEB J (2007) 21:3490-8. doi: 10.1096/fj.07-8661 com

29. Koch-Nolte F, Duffy T, Nissen M, Kahl S, Killeen N, Ablamunits V, et al. A New Monoclonal Antibody Detects a Developmentally Regulated Mouse Ecto-ADP-Ribosyltransferase on T Cells: Subset Distribution, Inbred Strain Variation, and Modulation Upon T Cell Activation. J Immunol (1999) 163:6014-22.

30. Scheuplein F, Schwarz N, Adriouch S, Krebs C, Bannas P, Rissiek B, et al. $\mathrm{NAD}+$ and ATP Released From Injured Cells Induce P2X7-Dependent Shedding of CD62L and Externalization of Phosphatidylserine by Murine T Cells. J Immunol (2009) 182:2898-908. doi: 10.4049/jimmunol.0801711
31. Wiśniewski JR, Zougman A, Nagaraj N, Mann M. Universal Sample Preparation Method for Proteome Analysis. Nat Methods (2009) 6:359-62. doi: 10.1038/nmeth.1322

32. Bilan V, Leutert M, Nanni P, Panse C, Hottiger MO. Combining HCD and EThcD Fragmentation in a Product Dependent-Manner Confidently Assigns Proteome-Wide ADP-Ribose Acceptor Sites. Anal Chem (2016) 89(3):152330. doi: 10.1021/acs.analchem.6b03365

33. Shannon P, Markiel A, Ozier O, Baliga NS, Wang JT, Ramage D, et al. Cytoscape: A Software Environment for Integrated Models of Biomolecular Interaction Networks. Genome Res (2003) 13:2498-504. doi: 10.1101/gr.1239303

34. Szklarczyk D, Gable AL, Lyon D, Junge A, Wyder S, Huerta-Cepas J, et al. STRING V11: Protein-Protein Association Networks With Increased Coverage, Supporting Functional Discovery in Genome-Wide Experimental Datasets. Nucleic Acids Res (2018) 47:D607-13. doi: 10.1093/nar/gky1131

35. Doncheva NT, Morris JH, Gorodkin J, Jensen LJ. Cytoscape StringApp: Network Analysis and Visualization of Proteomics Data. J Proteome Res (2018) 18:623-32. doi: 10.1021/acs.jproteome.8b00702

36. Gehrig PM, Nowak K, Panse C, Leutert M, Grossmann J, Schlapbach R, et al. Gas-Phase Fragmentation of ADP-Ribosylated Peptides: Arginine-Specific Side-Chain Losses and Their Implication in Database Searches. J Am Soc Mass Spectrom (2021) 32:157-68. doi: 10.1021/jasms.0c00040

37. Zimmermann $\mathrm{H}$, Zebisch $\mathrm{M}$, Sträter N. Cellular Function and Molecular Structure of Ecto-Nucleotidases. Purinergic Signal (2012) 8:437-502. doi: $10.1007 / \mathrm{s} 11302-012-9309-4$

38. Iwata H, Goettsch C, Sharma A, Ricchiuto P, Goh WWB, Halu A, et al. PARP9 and PARP14 Cross-Regulate Macrophage Activation Via STAT1 ADP-Ribosylation. Nat Commun (2016) 7:12849. doi: 10.1038/ncomms12849

39. Huang S, Apasov S, Koshiba M, Sitkovsky M. Role of A2a Extracellular Adenosine Receptor-Mediated Signaling in Adenosine-Mediated Inhibition of T-Cell Activation and Expansion. Blood (1997) 90:1600-10. doi: 10.1182/ blood.V90.4.1600

40. Matthes M, Hollmann C, Bertuleit H, Kühl M, Thiele HG, Haag F, et al. "Natural" RT6-1 and RT6-2 "Knock-Out" Mice. Adv Exp Med Biol (1997) 419:271-4. doi: 10.1007/978-1-4419-8632-0_35

41. Koch-Nolte F, Klein J, Hollmann C, Kühl M, Haag F, Gaskins HR, et al. Defects in the Structure and Expression of the Genes for the T Cell Marker Rt6 in NZW and (NZB X NZW)F1 Mice. Int Immunol (1995) 7:883-90. doi: 10.1093/intimm/7.5.883

42. Er-Lukowiak M, Duan Y, Rassendren F, Ulmann L, Nicke A, Ufer F, et al. A P2rx7 Passenger Mutation Affects the Vitality and Function of T Cells in Congenic Mice. iScience (2020) 23:101870. doi: 10.1016/j.isci.2020.101870

43. Antonioli L, Pacher P, Vizi ES, Haskó G. CD39 and CD73 in Immunity and Inflammation. Trends Mol Med (2013) 19:355-67. doi: 10.1016/..molmed.2013.03.005

44. Jamal Z, Afkham-Ebrahimi A, Saggerson ED. A Novel Assay for 5'Nucleotidase Using 1,N6-Etheno-AMP as Substrate, and Comments on the Properties of the Reaction Product, Ethenoadenosine. Biochem J (1988) 250:369-73. doi: 10.1042/bj2500369

45. Jackson EK, Gillespie DG, Cheng D, Mi Z, Menshikova EV. Characterization of the N6-Etheno-Bridge Method to Assess Extracellular Metabolism of Adenine Nucleotides: Detection of a Possible Role for Purine Nucleoside Phosphorylase in Adenosine Metabolism. Purinergic Signal (2020) 16:187211. doi: 10.1007/s11302-020-09699-x

46. Mottahedeh J, Haffner MC, Grogan TR, Hashimoto T, Crowell PD, Beltran H, et al. CD38 Is Methylated in Prostate Cancer and Regulates Extracellular NAD. Cancer Metab (2018) 6:13. doi: 10.1186/s40170-018-0186-3

47. Briceño P, Rivas-Yáñez E, Rosemblatt MV, Parra-Tello B, Farías P, Vargas L, et al. CD73 Ectonucleotidase Restrains CD8+ T Cell Metabolic Fitness and Anti-Tumoral Activity. Front Cell Dev Biol (2021) 9:638037. doi: 10.3389/fcell.2021.638037

48. Menzel S, Rissiek B, Bannas P, Jakoby T, Miksiewicz M, Schwarz N, et al. Nucleotide-Induced Membrane-Proximal Proteolysis Controls the Substrate Specificity of T Cell Ecto-ADP-Ribosyltransferase ARTC2.2. J Immunol (2015) 195(5):2057-66. doi: 10.4049/jimmunol.1401677

49. Schneider E, Rissiek A, Winzer R, Puig B, Rissiek B, Haag F, et al. Generation and Function of Non-Cell-Bound CD73 in Inflammation. Front Immun (2019) 10:1729. doi: 10.3389/fimmu.2019.01729

50. Menzel S, Koudelka T, Rissiek B, Haag F, Meyer-Schwesinger C, Tholey A, et al. ADP-Ribosylation Regulates the Signaling Function of IFN- $\gamma$. Front Immun (2021) 12:642545. doi: 10.3389/fimmu.2021.642545 
Conflict of Interest: FK-N receives royalties from sales of antibodies developed in the lab via MediGate $\mathrm{GmbH}$, a 100\% subsidiary of the University Medical Center, Hamburg.

The remaining authors declare that the research was conducted in the absence of any commercial or financial relationships that could be construed as a potential conflict of interest.

Publisher's Note: All claims expressed in this article are solely those of the authors and do not necessarily represent those of their affiliated organizations, or those of the publisher, the editors and the reviewers. Any product that may be evaluated in this article, or claim that may be made by its manufacturer, is not guaranteed or endorsed by the publisher.

Copyright (C) 2021 Leutert, Duan, Winzer, Menzel, Tolosa, Magnus, Hottiger, Koch-Nolte and Rissiek. This is an open-access article distributed under the terms of the Creative Commons Attribution License (CC BY). The use, distribution or reproduction in other forums is permitted, provided the original author(s) and the copyright owner(s) are credited and that the original publication in this journal is cited, in accordance with accepted academic practice. No use, distribution or reproduction is permitted which does not comply with these terms. 